\title{
A model for dynamical switching in tristable perception for visual plaids
}

\author{
Gemma Huguet $^{1 *}$, Jean-Michel Hupé ${ }^{2}$, John Rinzel ${ }^{1,3}$ \\ From Twenty First Annual Computational Neuroscience Meeting: CNS*2012 \\ Decatur, GA, USA. 21-26 July 2012
}

When observers view for extended time an ambiguous visual scene with two or more different interpretations they report switching between different perceptions. We focus on a classical paradigmatic stimulus, the visual plaids, consisting of two superimposed drifting gratings with transparent intersections [1,2]. For visual plaids, tristable perception is experienced: one coherent percept (the gratings move together as a single pattern) and two transparent percepts (the gratings slide across one another) with alternating depth order [3]. In order to decipher the complex mechanisms of tristable perception, we gathered a large amount of psychophysical data on tristable plaids and developed a neural network, firing rate model of interaction between neural populations that could account for the experimental results.

Nine subjects reported continuously the three possible percepts for 3 sessions of 10 stimuli each ( 3 minutes per stimulus). The angle between the vectors normal to gratings was equal to 80,100 or 120 degrees. We collected enough percepts to compute statistics for each subject and parameter without collapsing data [4].

As opposed to bistable stimuli where the only possibility is the alternation between the two percepts, in the tristable case the results show that the next percept probability depends on the previous percepts. Indeed, the sequence of perceptual switches confirms that switches between two transparency states are typically interleaved by a coherent percept, especially for values of the angle equal to 80 and $100[3,4]$. Moreover, by examining triplets consisting of two transparent percepts interleaved by a coherent one, we observed that the probability of the two transparent percepts in the triplet having the same depth pattern decreases as the duration of the coherent percept shortens.

\footnotetext{
* Correspondence: gh707@nyu.edu

'Courant Institute of Mathematical Sciences, New York University, New York, NY, 10012, USA

Full list of author information is available at the end of the article
}

These trends suggest that adaptation is implicated in perceptual alternations. For bistable alternations correlations are absent or insignificant.

We propose inhibition-based competition along with adaptation and noise in a multi-state framework as plausible mechanisms for the dynamics of perceptual switching. Our model is a firing rate model consisting of three mutually coupled populations of cells, each one encoding a different percept. It is based on the firing rate models for alternations during perceptual bistability [5]. We can explain the dependence in perceptual history by introducing an inhibition imbalance in the interactions between neural populations (the two transparent percepts inhibit each other more strongly than they inhibit the coherent state, making the latter more dominant and more likely to switch to). Adjusting the relative strength of adaptation and noise we can account for the dominance duration distributions and the switching probability between depth percepts as a function of the coherent percept duration. Finally, we consider other possible architectures for the model and we show that a non-hierarchical architecture where motion is encoded together with depth fits better with the experimental results.

\section{Acknowledgements}

Swartz Foundation and Agence Nationale de Recherche Grant ANR-08-BLAN0167-01

\section{Author details}

${ }^{1}$ Courant Institute of Mathematical Sciences, New York University, New York, NY, 10012, USA. ${ }^{2}$ CerCo, Toulouse University \& CNRS, Toulouse, France.

${ }^{3}$ Center for Neural Science, New York University, New York, NY, 10003, USA.

Published: 16 July 2012

\section{References \\ 1. Wallach H: Uber visuell wahrgenommene Bewegungsrichtung. Psychologische Forschung 1935, 20:325-380.}


2. Hupé JM, Rubin N: The dynamics of bi-stable alternation in ambiguous motion displays: a fresh look at plaids. Vision Res 2003, 43:531-548.

3. Hupé JM, Juillard V: Buildup of visual plaid segmentation and auditory streaming may be explained by the perception of these ambiguous stimuli being tristable rather than bistable. Program No. 652.162009. Neuroscience Meeting Planner Chicago, IL: Society for Neuroscience; 2009, Online.

4. Hupé JM: Dynamics of menage a trois in moving plaid ambiguous perception. J Vis 2010, 10(7):1217.

5. Moreno-Bote R, Rinzel J, Rubin N: Noise-induced alternations in an attractor network model of perceptual bistability. J. Neurophysiol 2007, 98:1125-1139.

doi:10.1186/1471-2202-13-S1-P59

Cite this article as: Huguet et al: A model for dynamical switching in tristable perception for visual plaids. BMC Neuroscience 2012 13(Suppl 1): P59.

Submit your next manuscript to BioMed Central and take full advantage of:

- Convenient online submission

- Thorough peer review

- No space constraints or color figure charges

- Immediate publication on acceptance

- Inclusion in PubMed, CAS, Scopus and Google Scholar

- Research which is freely available for redistribution

Submit your manuscript at www.biomedcentral.com/submit 